\title{
Long-term Results of Radiosurgery for Cerebral Arteriovenous Malformations
}

\author{
Magali Lecavalier-Barsoum, Daniel Roy, Robert Doucet, Bernard Fortin, \\ Carole Lambert, Robert Moumdjian, Jean-Paul Bahary
}

\begin{abstract}
Background: Stereotactic radiosurgery (SRS) is known to safely result in a high obliteration rate for small and medium sized arteriovenous malformations (AVM). Objective: To evaluate the long-term outcome of patients treated with SRS, with special emphasis given to obliteration and toxicity rates. Methods: We performed a review of 43 cerebral AVM patients, treated from 1998 to 2008 with a single SRS dose ranging from 21-25 Gy. Of these, 37 had a minimal follow-up of one year. Medical files were reviewed to assess patient and AVM characteristics, the SRS treatment, therapy prior to SRS, the obliteration rate and toxicities. Whenever necessary, outcome data was supplemented by telephone interviews with the patient or treating physician. Results: AVM size was $\geq 3 \mathrm{~cm}$ in diameter in $21 \%$ of patients. Five patients $(11.6 \%)$ underwent surgery prior to SRS and 31 patients $(72.1 \%)$ received one or more embolizations prior to SRS. Of the patients followed with angiography $\geq 1$ year post-SRS, 89\% (33/37) had a complete obliteration of the nidus, after a median time of 24.7 months post-treatment. Embolization prior to SRS was not predictive of outcome. One patient suffered a non-fatal haemorrhage between treatment and obliteration. The rate of symptomatic radiation-induced radiological changes was $8.1 \%$. Conclusion: Our study shows both obliteration and complication rates in the upper limit of those reported in the literature. SRS seems an attractive treatment option for small AVMs. Unlike other reports, the prior use of embolization did not impact negatively on obliteration rates.
\end{abstract}

RÉSUMÉ: Résultats à long terme de la radiochirurgie dans le traitement des malformations artérioveineuses cérébrales. Contexte : Il est bien connu que le taux d'oblitération par la radiochirurgie stéréotaxique (RCS) des malformations artérioveineuses (MAV) de petite taille et de taille moyenne est élevé. Objectif : Le but de cette étude était d'évaluer les résultats à long terme chez des patients traités par RCS et nous mettons l'emphase sur les taux d'oblitération et de toxicité. Méthode : Nous avons effectué une revue des dossiers de 43 patients atteints d'une MAV qui ont été traités entre 1998 et 2008 par une dose unique de RCS de 21 à 25 Gy. Chez 37 de ces patients, le suivi était d'au moins 1 an. Les dossiers ont été revus pour examiner les caractéristiques des patients et des MAV, le traitement RCS, le traitement antérieur à la RCS, le taux d'oblitération et les manifestations de toxicité. Lorsque nécessaire, les données sur le résultat du traitement ont été complétées par une entrevue téléphonique avec le patient ou le médecin traitant. Résultats : Le diamètre de la MAV était de $3 \mathrm{~cm}$ ou plus chez $21 \%$ des patients. Cinq patients $(11,6 \%)$ avaient subi une chirurgie avant la RCS et 31 patients $(72,1 \%)$ avaient subi au moins une embolisation avant la RCS. Chez les patients suivis par angiographie un an ou plus après la RCS, $89 \%$ (33/37) avaient une oblitération complète du foyer après un délai médian de 24,7 mois après le traitement. L'embolisation avant la RCS n'était pas un facteur prédictif du résultat. Un patient a subi une hémorragie non fatale entre le traitement et l'oblitération. Le taux de changements radiologiques symptomatiques induits par la radiation était de $8,1 \%$. Conclusion : Notre étude démontre des taux d'oblitération et de complications qui sont à la limite supérieure de ceux rapportés dans la littérature. La RCS semble une option de traitement avantageuse pour les petites MAV. Contrairement à ce qui est rapporté dans d'autres publications, le traitement antérieur par embolisation n'a pas eu d'impact négatif sur le taux d'oblitération.

Can J Neurol Sci. 2013; 40: 182-186

Arteriovenous malformations (AVM) are groups of blood vessels in which arteries and veins have an abnormal connection, without intervening capillaries, allowing shunting of blood in a central nidus. Although they represent only $11 \%$ of cerebrovascular malformations, they are the most likely to be symptomatic, with presentations including seizures and spontaneous haemorrhages.

Therapeutic modalities include embolization, surgery and stereotactic radiosurgery (SRS). They can be used alone or in combination. Factors influencing the choice of therapy are mainly localization and size of the AVM, with those located in eloquent locations and of large size representing a significant surgical risk. Stereotactic radiosurgery is known to offer a high obliteration rate for small and medium size lesions, with low morbidity. However, obliteration usually occurs after a latency period that can extend from one to four years. The risk of haemorrhage persists during this latency period.

We reviewed the characteristics and long-term outcome of patients with AVM treated with SRS at a single institution, with special attention to obliteration and late complication rates.

From the Radiation Oncology Department (MLB), McGill University Health Center (MUHC); Radiology Department (DR), Radiation Oncology Department (RD, BF, CL, JPB), Neurosurgery Department (RM), Centre hospitalier de l'Université de Montréal (CHUM), Montreal, Quebec, Canada.

Received December 20, 2011. Final Revisions Submitted October 24, 2012. Correspondence to: Magali Lecavalier-Barsoum, McGill University Health Center, 1650 av. Cedar, Montreal, Quebec, H3G 1A4, Canada.

Email: Magali.lecavalier@mail.mcgill.ca. 


\section{Material AND Methods}

\section{Patients}

We performed a retrospective review of all cerebral AVM patients treated in the Radiation Oncology Department of the Centre Hospitalier de l'Université de Montréal, Notre-Dame Hospital, between 1998 and 2008. Records from a total of 43 patients were retrieved and included in this review. All clinical and radiological records were carefully reviewed for demographics, including AVM characteristics, treatment details and outcomes. Imaging was thoroughly reviewed by a neuroradiologist (D.R.). The size of the AVM was documented at the time of treatment planning.

\section{Radiosurgery technique}

Patients underwent a computed tomographic (CT) scan of the brain as well as a stereotactic angiography. Every patient had a stereotactic head frame placed under local anaesthesia on the day of treatment by a neurosurgeon. The irradiation was delivered by a linear accelerator (LINAC) with energy of $6 \mathrm{MV}$. All patients received a single treatment, with doses ranging from 21 to $25 \mathrm{~Gy}$, (median dose of $24 \mathrm{~Gy}$ ). The dose was prescribed to the $70 \%$ to $92 \%$ isodose surface, which typically included the entire AVM nidus volume. For those patients who underwent previous embolization, the SRS treatment volume did not include the successfully embolized volumes.

\section{Clinical follow-up}

After SRS, patients typically underwent repeat imaging studies at 6, 12 and 24 months, although not all patients were systematically followed clinically and radiologically because they were followed at different centers. A total of 37 patients had a minimal clinical and imaging follow-up of at least one year and

Table 1: Modified Rankin score

\begin{tabular}{c|l}
\hline Score & \multicolumn{1}{c}{ Definition } \\
\hline 0 & $\begin{array}{l}\text { No symptoms at all } \\
\text { No significant disability despite symptoms; } \\
\text { able to carry out all usual duties and activities }\end{array}$ \\
2 & $\begin{array}{l}\text { Slight disability; unable to carry out all } \\
\text { previous activities, no need for assistance }\end{array}$ \\
3 & $\begin{array}{l}\text { Moderate disability; requiring some help, } \\
\text { but able to walk without assistance }\end{array}$ \\
4 & $\begin{array}{l}\text { Moderately severe disability; unable to walk and } \\
\text { to attend to own bodily needs without assistance }\end{array}$ \\
5 & $\begin{array}{l}\text { Severe disability; bedridden, incontinent and } \\
\text { requiring constant nursing care and attention }\end{array}$ \\
\hline
\end{tabular}

this is the group of patients assessed for angiographic response to the SRS. The occurrence of adverse events was retrieved from the medical records and supplemented by telephone contact with the patient, patient's family or treating physician. The obliteration prediction index, as described by Schwartz et $\mathrm{al}^{1}$, was used to calculate the probability of obliteration post-SRS. Arteriovenous malformations obliteration was defined as the resolution of arteriovenous shunting as evidenced by the absence of flow within the lesion by digital angiography. The date of obliteration was considered to be the date the angiography demonstrating the obliteration was performed. The modified Rankin scale ${ }^{2}$ was used to assess the degree of dependence in daily life activities of the patients. Whenever needed, telephone interviews were conducted in order to establish the score. A total of 36 patients were reached by this method in order to update the required information. Details of the modified Rankin scale are found in Table 1.

\section{Results}

\section{Patient and AVM characteristics}

The majority of patients were males $(58 \%)$. The median age was 37 years (range 12 to 65 years). Only one patient was under

Table 2: Patient and AVM characteristics

\begin{tabular}{|c|c|c|}
\hline Characteristic & & Number of patients \\
\hline Median age (range) & 37 years $(12-65)$ & \\
\hline \multicolumn{3}{|l|}{$\underline{\text { Gender }}$} \\
\hline Male & & $25(58.1 \%)$ \\
\hline Female & & $18(41.9 \%)$ \\
\hline \multicolumn{3}{|l|}{$\underline{\text { Presentation at diagnosis }}$} \\
\hline Haemorrhage & & $31(72.1 \%)$ \\
\hline Seizure & & $5(11.9 \%)$ \\
\hline Neurologic symptom(s) & & $3(7.1 \%)$ \\
\hline Headache & & $2(4.8 \%)$ \\
\hline No symptom & & $2(4.8 \%)$ \\
\hline Median follow-up (range) & 23.5 months $(0-126.2)$ & \\
\hline \multicolumn{3}{|l|}{$\underline{\text { AVM size }}$} \\
\hline$<3 \mathrm{~cm}$ & & $34(79.1 \%)$ \\
\hline$\geq 3 \mathrm{~cm}$ & & $9(20.9 \%)$ \\
\hline Median & $1.7 \mathrm{~cm}$ & \\
\hline \multicolumn{3}{|l|}{ Spetzler-Martin grade } \\
\hline I & & $6(14.0 \%)$ \\
\hline II & & $21(48.8 \%)$ \\
\hline III & & $14(32.6 \%)$ \\
\hline IV & & $2(4.7 \%)$ \\
\hline $\mathrm{V}$ & & 0 \\
\hline
\end{tabular}

$\mathrm{AVM}=$ arteriovenous malformation 
Table 3: Effect of embolization prior to radiosurgery

\begin{tabular}{l|l|l}
\hline & $\begin{array}{l}\text { Embolization } \\
(\mathrm{N}=26)\end{array}$ & $\begin{array}{l}\text { No embolization } \\
(\mathrm{N}=11)\end{array}$ \\
\hline Obliteration rate & $92.3 \%$ & $81.8 \%$ \\
\hline Average size $(\mathrm{cm})$ & 1.8 & 1.8 \\
\hline Average SRS dose & 24.3 & 24.0 \\
(Gy) & & \\
\hline
\end{tabular}

$\mathrm{cm}=$ centimetre $; \mathrm{Gy}=$ Gray; $\mathrm{SRS}=$ stereotactic radiosurgery

the age of 18 at the time of treatment. The most frequent presentation was haemorrhage (30/43 patients; $71.4 \%$ ). Seizure was the presenting symptom of five patients (12\%). A total of five patients $(12 \%)$ had other neurological symptoms such as dysphasia, hemiparesis and headache. Moreover, in two patients (4.8\%) the AVM diagnosis was an incidental finding: one of the patients was under investigation for amenorrhea, whereas the other was being followed for a previously treated AVM and was found to have a second one on follow-up imaging.

Embolization prior to SRS was common, with 18 patients $(41.9 \%)$ having undergone this treatment once, ten patients (23.2\%) having undergone this treatment twice and three patients $(7.0 \%)$ having undergone this treatment on three occasions. Surgery for the AVM prior to SRS was less common, with only three patients $(7.0 \%)$ undergoing the procedure once and two patients $(4.6 \%)$ undergoing the procedure twice. The diameter of AVMs ranged from $1 \mathrm{~cm}$ to $3.84 \mathrm{~cm}$ (median $1.7 \mathrm{~cm}$ ). The Spetzler-Martin grade varied between I and IV. The median obliteration prediction index was calculated at 15.7 (range 5.5 to 25; mean 15.3). Table 2 summarizes patient and AVM characteristics.

\section{Radiosurgical outcomes}

The obliteration rate based on angiography criteria was $89.2 \%$. One patient developed a non-fatal haemorrhage postSRS, occurring 918 days post-treatment. She had a confirmed angiographic obliteration one year after the bleeding episode.

When evaluating patients with pre-SRS embolization, of the 31 patients undergoing a previous embolization, $24(77.4 \%)$ of them achieved a complete angiographic obliteration. For those with a follow-up of one year or more, 92.3\% (24/26) achieved an angiographic obliteration. In patients without embolization, nine out of the $12(75 \%)$ achieved a complete obliteration. Similarly, in those with a minimum one year angiographic follow-up, nine out of eleven were found to have a complete obliteration (82\%). By Fisher's exact test, the difference in obliteration rates between patients undergoing embolization or not and with a minimum follow-up of one year was not statistically significant ( $p=0.341$ ). The analysis of the effect of embolization prior to SRS can be found in Table 3 .

Based on the dose delivered to and the diameter of the AVM, Schwartz et $\mathrm{al}^{1}$ developed an obliteration prediction index (OPI) to guide physicians in determining the chance of obliterating the malformation post-SRS. When we compare sub-groups with similar OPI from our study to Schwartz' study, it appears that our cohort had higher than expected obliteration rates (Table 4). However, a note of caution should be added because, in the original study by Schwartz and colleagues, patients undergoing previous embolization were not included in the analysis.

\section{Adverse effects and death}

Of the 37 patients with a follow-up of at least one year, six $(16.2 \%)$ were found to have radiological evidence of radiationinduced changes, characterized by magnetic resonance imaging (MRI) evidence of T2-enhancing mass with white matter changes and edema within or immediately adjacent to the site of the original lesion. These radiological changes occurred at a median of 16 months post-treatment. However, only three $(8.1 \%)$ of them were symptomatic. One patient presented right hemianopsia and right sided ataxia 7.8 months after SRS. On MRI, there was evidence of ischemic lesions thought to be secondary to radiation-induced arteritis. A second patient

Table 4: Obliteration prediction index (OPI)

\begin{tabular}{|c|c|c|c|c|c|}
\hline OPI sub-groups & Mean OPI & $\begin{array}{l}\text { Number of } \\
\text { patients }\end{array}$ & $\begin{array}{l}\text { Number of } \\
\text { obliterations }\end{array}$ & P(oblit) CHUM data & $\begin{array}{l}\mathrm{P}(\text { oblit }) \text { exponential fit } \\
\text { from Toronto data }\end{array}$ \\
\hline$<4$ & - & & & & \\
\hline $4-8$ & 7.1 & 5 & 5 & $100 \%$ & $49 \%$ \\
\hline $8-12$ & 10.8 & 7 & 5 & $71 \%$ & $67 \%$ \\
\hline $12-20$ & 16.3 & 19 & 17 & $89 \%$ & $82 \%$ \\
\hline$>20$ & 23.6 & 6 & 6 & $100 \%$ & $92 \%$ \\
\hline
\end{tabular}


Table 5: Characteristics of patients with radiological radiation induced changes

\begin{tabular}{|c|c|c|c|c|c|c|c|c|}
\hline & Patient & $\begin{array}{l}\text { AVM } \\
\text { diameter }(\mathrm{cm})\end{array}$ & $\begin{array}{l}\text { AVM Spetzler- } \\
\text { Martin score }\end{array}$ & $\begin{array}{l}\text { Prior } \\
\text { embolization }\end{array}$ & $\begin{array}{l}\text { Dose } \\
\text { (Gy) }\end{array}$ & Obliteration & $\begin{array}{l}\text { Time to radiation induced } \\
\text { changes (months) }\end{array}$ & $\begin{array}{l}\text { Rankin } \\
\text { score }\end{array}$ \\
\hline \multirow{3}{*}{ 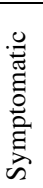 } & 1 & 2.00 & II & No & 25 & yes & 7.8 & 2 \\
\hline & 2 & 3.36 & III & Yes & 24 & yes & 63.8 & 2 \\
\hline & 3 & 3.70 & IV & Yes & 25 & Unknown & 14.0 & 6 \\
\hline \multirow{3}{*}{ 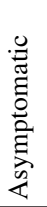 } & 4 & 2.00 & I & Yes & 24 & yes & 16.8 & 1 \\
\hline & 5 & 1.50 & III & Yes & 22 & yes & 15.2 & 3 \\
\hline & 6 & 1.00 & III & Yes & 25 & yes & 19.8 & 1 \\
\hline
\end{tabular}

$\mathrm{AVM}=$ arteriovenous malformation; $\mathrm{Gy}=$ Gray

presented with speech problems 63.8 months after treatment and required surgical resection of an area of radionecrosis, confirmed by pathology. The angiographic study she had undergone 52 months post-treatment showed a complete obliteration of her AVM. The symptoms lasted between one and two months, and when reached by telephone, the patient mentioned that the neurological problem had resolved since surgery. The third patient with symptomatic radiological changes had a grade IV AVM, with a diameter of $3.7 \mathrm{~cm}$. He presented with right hemiparesthesia one year post treatment, and was found to have MRI findings in keeping with radionecrosis. Unfortunately, angiography was never performed after treatment, thus no information on the patency or obliteration of the AVM is available. He passed away four years post-treatment, and the cause of death was not found in the medical files. By the time the article was written (September 2012), this was the only patient who had died. Only one of the six patients suffering post-SRS complications had not undergone previous embolization. Characteristics of patients with radiation induced changes can be found in Table 5 .

\section{Rankin score}

The modified Rankin median score was 2, with the mode being 1 . Half of the 36 patients assessed declared suffering from no symptoms or only light symptoms not impairing their daily life activities (score $0-1)$. Ten patients $(27.8 \%)$ report a change in their previous activities because of symptoms, without need for assistance (score 2). Seven patients (19.4\%) described having moderate disability requiring help in their daily life, without requiring help to walk or for personal hygiene. No patient defined their symptoms as inducing severe disability. The patient deceased at the time of the assessment was attributed a score of 6. Furthermore, the Rankin score was also measured for those patients with radiation-induced radiological changes. The three patients with symptomatic radiation-induced radiological changes had Rankin scores of 2, 2 and 6, while the other three patients with asymptomatic changes had scores of 1,2 and 3 .

\section{Discussion}

Our study aimed at analysing the effectiveness of SRS for the treatment of AVM in a group of patients heavily pretreated prior to SRS. We found an obliteration rate three years after treatment of $89.2 \%$, with only one haemorrhage occurring during the latency period, and a symptomatic radiation induced changes rate of $8.1 \%$. In the literature, SRS has proven effective in treating small AVMs, with complete occlusion rates reported between 72 and $80 \%$ 3-7.

Colombo, et al, ${ }^{3}$ studied the outcome of a similar cohort, with 97 patients treated by LINAC for AVMs measuring between 0.4 and $4 \mathrm{~cm}$. The doses delivered varied between 18.7 and $40 \mathrm{~Gy}$. The obliteration rate at one year was of $52 \%$, and of 75 at two years. Friedman ${ }^{8}$ reported on 158 patients treated with LINAC for lesions between 0.5 and $43.5 \mathrm{cc}$ (median of $7.1 \mathrm{cc}$ ) with doses between 10 and 25Gy. The obliteration rate at two years was $80 \%$. Yamamoto ${ }^{5}$ published a report in 1995 on 121 patients treated with the Leskell cobalt-60 gamma unit. The doses were adjusted to the size of the AVM, with 20 Gy given to lesions less than $2.0 \mathrm{~cm}$ in diameter; 18 Gy for lesions 2.1 to $3.0 \mathrm{~cm}$ in diameter; and 16 Gy for lesions over $3.0 \mathrm{~cm}$. An obliteration rate of $74.5 \%$ at three years was reported.

Some authors have suggested that embolization prior to SRS negatively impacts on the obliteration rate. In a study published in 2007, Andrade-Souza et $\mathrm{al}^{9}$ compared patients treated with embolization plus SRS (Group A) and patients treated with SRS alone (Group B). The two groups consisted of 47 patients matched for AVM size, location and marginal dose. The obliteration rate was $70 \%$ in Group B, compared to $47 \%$ in group A. This difference was statistically significant $(\mathrm{p}=0.036)$. This study is not one of a kind, as Pollock et $\mathrm{al}^{10}$, Schlienger et al ${ }^{11}$ and Miyawaki et $\mathrm{al}^{12}$ all found prior embolization to have an independent negative association with obliteration after SRS. Recently, Kano et $\mathrm{al}^{13}$ reported on 120 patients treated at the University of Pittsburgh with embolization prior to SRS and also reported a reduced rate of obliteration as compared to those patients undergoing SRS alone. 
In our series, the complete obliteration rate in patients with embolization prior to SRS is in the upper limit of those reported in the literature for small AVM. This difference may be purely related to the relatively smaller size of the AVMs treated at our institution. The AVMs in our study were smaller than those reported by Andrade-Souza et $\mathrm{al}^{9}$ (median AVM size of $1.7 \mathrm{~cm}$ vs. $2.5 \mathrm{~cm}$ ). One of the purposes of embolization prior to SRS is to reduce the size of the nidus, allowing for a safer delivery of SRS for those patients presenting with large AVMs. However, embolization in large lesions can make it harder to appropriately define the target volume, leading to smaller treatment volumes and negatively impacting on the obliteration rate.

One of the concerns with the use of SRS for cerebral AVMs is the potential development of radiation induced radiological changes. The incidence of radionecrosis post SRS in patients not previously embolized ranges from 1.3 to $9 \%^{3,4,14}$. Patients undergoing pre-SRS embolization may be at higher risk of developing complications. Colombo et $\mathrm{al}^{3}$ report rates of radionecrosis of $6.2 \%$, with $3 \%$ being symptomatic. A review of six studies on SRS for AVM was performed by Marks and Spencer ${ }^{14}$, and they found a $9 \%$ rate of clinically significant neurological symptoms attributed to the SRS. They did not have a radiological assessment. Our rate of $8.1 \%$ of symptomatic radionecrosis is within the limits of what is found in the literature.

\section{Conclusion}

Our study reports a high obliteration rate and an acceptable complication rate in a selected group of patients with relatively small AVMs who underwent embolization prior to SRS. Whether the pre-SRS embolization procedures lead to a higher rate of obliteration remains to be determined.

\section{REFERENCES}

1. Schwartz M, Sixel K, Young C, et al. Prediction of obliteration of arteriovenous malformations after radiosurgery: the obliteration prediction index. Can J Neurol Sci. 1997 May;24 (2):106-9.

2. United Kingdom transient ischaemic attack (UK-TIA) aspirin trial: interim results. UK-TIA Study Group. Br Med J (Clin Res Ed). 1988 Jan 30;296(6618):316-20.

3. Colombo F, Benedetti A, Pozza F, Marchetti C, Chierego G. Linear accelerator radiosurgery of cerebral arteriovenous malformations. Neurosurgery. 1989 Jun;24(6):833-40.

4. Friedman WA, Bova FJ. Linear accelerator radiosurgery for arteriovenous malformations. J Neurosurg. 1992 Dec;77(6): 832-41.

5. Yamamoto Y, Coffey RJ, Nichols DA, Shaw EG. Interim report on the radiosurgical treatment of cerebral arteriovenous malformations. The influence of size, dose, time, and technical factors on obliteration rate. J Neurosurg. 1995 Nov;83(5):832-7.

6. Herbert C, Moiseenko V, McKenzie M, et al. Factors predictive of obliteration after arteriovenous malformation radiosurgery. Can J Neurol Sci. 2011 Nov;38(6):845-50.

7. Skjoth-Rasmussen J, Roed H, Ohlhues L, Jespersen B, Juhler M. Complications following linear accelerator based stereotactic radiation for cerebral arteriovenous malformations. Int J Radiat Oncol Biol Phys. 2010 Jun 1;77(2):542-7.

8. Friedman WA, Bova FJ, Mendenhall WM. Linear accelerator radiosurgery for arteriovenous malformations: the relationship of size to outcome. J Neurosurg. 1995 Feb;82(2):180-9.

9. Andrade-Souza YM, Ramani M, Scora D, Tsao MN, terBrugge K, Schwartz ML. Embolization before radiosurgery reduces the obliteration rate of arteriovenous malformations. Neurosurgery. 2007 Mar;60(3):443-51; discussion 51-2.

10. Pollock BE, Flickinger JC, Lunsford LD, Maitz A, Kondziolka D. Factors associated with successful arteriovenous malformation radiosurgery. Neurosurgery. 1998 Jun;42(6):1239-44; discussion 44-7.

11. Schlienger M, Atlan D, Lefkopoulos D, et al. Linac radiosurgery for cerebral arteriovenous malformations: results in 169 patients. Int J Radiat Oncol Biol Phys. 2000 Mar 15;46(5):1135-42.

12. Miyawaki L, Dowd C, Wara W, et al. Five year results of LINAC radiosurgery for arteriovenous malformations: outcome for large AVMS. Int J Radiat Oncol Biol Phys. 1999 Jul 15;44(5): 1089-106.

13. Kano H, Kondziolka D, Flickinger JC, et al. Stereotactic radiosurgery for arteriovenous malformations after embolization: a case-control study. J Neurosurg. 2012 Aug;117 (2):265-75.

14. Marks LB, Spencer DP. The influence of volume on the tolerance of the brain to radiosurgery. J Neurosurgery. 1991 Aug;75(2): $177-80$. 